\title{
Age and Gender Effect in Phonetic Perception and Production
}

\author{
Zohreh Kassaian \\ English Department, Faculty of Foreign Languages, University of Isfahan, Isfahan, Iran \\ Email: kassaian@fgn.ui.ac.ir; zkassaian@yahoo.com
}

\begin{abstract}
The aim of this study was primarily to find the relationship between age and the perception and production of English speech sounds by Persian speakers. The researcher also tried to find out the relationship between gender and the discrimination and production of English speech sounds. Sixty subjects took part in this study. They were divided in two groups of thirty children and adults, including fifteen males and fifteen females each. Both groups participated in tests of discrimination and production of English sounds. Two ANOVAs were administered, the results of which supported the idea that children and adults have equal aptitude for perception and production of the English sounds, which implies that there is still room for an innate faculty to continue its work in adulthood. Moreover, gender was not found to be an influential factor regarding perception and production of English sounds. The performance of both groups was significantly superior in production rather than discrimination. This result shows that perception of sounds does not necessarily precede their production.
\end{abstract}

Index Terms - perception, production, discrimination, speech sounds, gender

\section{INTRODUCTION}

Age effect has been one of the topics most frequently considered in second language acquisition (SLA) research. Several books (Birdsong, 1999; Harley, 1986; Singleton \& Lengyel, 1995) and numerous articles have dealt with the topic from various theoretical perspectives.

Research findings show opposing results regarding the effect of age on second/foreign language learning. One view states that acquiring a language (native or foreign) is a natural achievement for children and becomes more difficult as one becomes older (Guasti, 2002). This statement is supported by the belief that there exists a critical period during which the ability to acquire the competence reaches its peak, and after which this ability declines. Lenneberg (1967) suggested that full development of language is possible only if it is acquired before puberty. Bickerton (1981) made strong statements in favor of critical period before and after which certain abilities do not develop. Repeated claims have been made for a 'critical period' for speech, usually located around puberty, after which the capacity to acquire native like speech is hypothetically impaired (Patkowski, 1990; Scovel, 1988). Concerning second/foreign language learning, researchers have assumed the possibility of extrapolating the critical period hypothesis to second/foreign language context (Scovel 1988; Long 1990b; Jonson 1992; Flege 1987; Morris et al. 1986; Patkowski 1990). The argument is that a critical point for SLA occurs around puberty, beyond which people seem to be relatively incapable of acquiring a native like accent of the second language (SL). Flege, Yeni-Komshian, \& Liu (1999) showed that a foreign accent can already be detected in individuals' first exposure to a foreign language at age 3 and that accents get stronger as age of first exposure increases.

\section{A. Child Advantage}

Regarding the relationship between age and pronunciation, several studies give advantage to children. Oyama (1976) found evidence for the advantage of children over adults in second-language learning. He stated that pronunciation is achieved better at earlier ages. Cochrane and Sachs (1979) made a comparison between children and adults on imitation of Spanish words and found children to be superior in imitative tasks and suggested that they may possess some special aptitude for phonological acquisition. Guiora, Brannon, and Dull (1972) believe that children's advantage over adults is due to the fact that they do not consider trying new sounds a risk and are not so worried about social acceptance by peers, while adults feel more at home with their established native language and have stress when trying to speak a foreign language (FL) at the prospect of sounding foolish.

\section{B. Adult Advantage}

A number of studies regarding the relationship between age and pronunciation give advantage to adults. Stern (1976) believes that adult cognitive ability to reason is more important than advantages children appear to have in pronunciation. Asher and Price (1967) suggested an advantage for adults believing that the hierarchical nature of process would be more easily understood by mature adults rather than by children. A study conducted by Snow and Hoefnages-Hohle (1978) did not support the "critical age" theory; in fact, the older group performed better than the younger children. Rosenman (1987) concluded in his study that young English speaking adults discriminate and are able 
to reproduce Spanish sounds better than children. Neufeld (1979) argued that he was able to teach second language learners to perform like natives on certain tasks after specialized training. A number of studies over the past ten years (Birdsong, 1999; Bongaerts, 1999; Marinova-Todd, Marshall \& Snow, 2000) have observed native like attainment among late learners (i.e., people immersed in the second language (L2) in their early teens and beyond,). Hudson (2000) has assumed two main versions of the critical period hypothesis for language learning: the 'maturation' and 'exercise' version. According to the exercise version, he believed, adults should be as able as children, at least biologically, to learn languages.

\section{Gender Factor}

Regarding females and males, several sociophonetic speech differences have been reported in the literature (Trudgill, 1972; Kramer, 1978; Byrd, 1994). Stolten and Engstrand (2002) state that it is a commonly held belief that older speakers are more dialectal than younger speakers and the clearest difference in dialect strength would be found between older men (most dialectal) and younger women (least dialectal).

\section{Perception versus Production}

Research concerned with the relationship between the production and perception of the sounds of an L2 has shown that a complex relationship exists between the production and perception of L2 sounds, and that many factors have to be taken into account in describing this interaction. A problem that researchers address is whether production precedes perception or, conversely, perception precedes production in the process of acquiring an L2. The question is: Can learners adequately pronounce sounds which are not well perceived, or is a good perception a prerequisite to accurate pronunciations?

The idea that inaccurate perceptual representations are responsible for non-native productions has been formulated in many of Flege's (1991) contributions stating that foreign accent may result from the development of the L1 phonetic system, which makes it increasingly unlikely that similar sounds in an L2 will evade being equated with sounds in L1. This phenomenon has been defined as "equivalence classification". According to this principle perception of a new phonetic contrast must necessarily precede its production.

Some observations made by Neufeld (1988) and Briére (1966) point out that when learning an L2 not all the sounds that are correctly perceived will be correctly produced. Some research point out towards a better differentiation between the two languages in production than in perception. The explanation suggested by Mack (1989) is similar to the one proposed by Sheldon (1985) to account for the same trend in L2 speakers: the social consequences of non-native production are more important than those of non-native perception and, therefore, accurate productions are found whereas perception can be different from monolinguals, whenever comprehension is achieved. It seems then, that in certain cases, the production of L2 sounds might precede their perception.

\section{RESEARCH QUESTIONS AND HYPOTHESES}

Concerning the contradictory results of the studies mentioned in the literature, this study intends to find out the effects of gender and age on the perception and production of English sounds in an Iranian environment. It specifically intends to shed light on (1) whether the age plays a significant role in learning English language sounds, (2) whether there is a relationship between gender and speech sound acquisition, and (3) whether there is any difference between two aspects of foreign-language skills; namely, auditory discrimination and oral production of sounds.

Based on the abovementioned questions the following null hypotheses can be formulated.

1. There is no difference between children and adults concerning perception and production of speech sounds.

2. There is no difference between males and females concerning perception and production of speech sounds.

3. There is no difference between auditory discrimination and oral production of sounds as two aspects of foreign language skills.

\section{METHOD}

\section{A. Participants}

Two groups of monolingual Persian children and adults, consisting of 30 people each, took part in phonetic discrimination and production of English sounds. Half of each group were females. The children group were selected from boys and girls participating in summer classes in Isfahan. These children had not been exposed to English language before, and the experimental tests were their first exposure. Their ages ranged from 8 to 10. The adult group consisted of 15 boys and 15 girls selected from a population who had not been exposed to English before taking part in this study either. Their age ranged between 36 and 48 years.

\section{B. Instruments}

Two tests were constructed for measuring auditory discrimination and oral production of English sounds. The test of oral production consisted of 45 items. Three initial and two final items were not included in the measurement. These items were one-syllable or two-syllable English words. Some of the sounds used in these words were non-existant in Persian such as the initial sounds of then, and thank and the short vowels in full and bud (Table 1). 
TABLE 1

TEST OF ORAL PRODUCTION

\begin{tabular}{|l|l|l|l|l|l|}
\hline Item & C & I & Item & C & I \\
\hline 1.ski & & & 24. well & & \\
\hline 2. get & & & 25. man & & \\
\hline 3. teacher & & & 26.cod & & \\
\hline 4. dentist & & & 27. bud & & \\
\hline 5. thank & & & 28. look & & \\
\hline 6. then & & & 29. full & & \\
\hline 7. sing & & & 30. feel & & \\
\hline 8. file & & & 31. tear & & \\
\hline 9. ring & & & 32. phone & & \\
\hline 10. button & & & 33. boat & & \\
\hline 11. bottle & & & 34. tide & & \\
\hline 12. went & & & 35. bought & & \\
\hline 13. speak & & & 36. tail & & \\
\hline 14. cute & & & 37. steam & & \\
\hline 15. queen & & & 38. atom & & \\
\hline 16. shrink & & & 39. class & & \\
\hline 17. school & & & 40. flunk & & \\
\hline 18. sheet & & & 41. strong & & \\
\hline 19. clap & & & 42. mere & & \\
\hline 20. street & & & 43. thinks & & \\
\hline 21. student & & & 44. spot & & \\
\hline 22. squint & & & 45. book & & \\
\hline 23. did & & & & & \\
\hline
\end{tabular}

The test was recorded by a female native American. Each word was followed by a pause. Each subject produced the word during the pause, and the responses were recorded on tape. Judges, who were native American English speakers listened to these recordings later and checked the marked ( underlined) English sounds as correct (C), or incorrect (I) depending on the accuracy of pronunciation.

The Wepman Auditory Discrimination Test (1973), which is a standardized test designed to determine the ability of children (ages 5 through 8) to recognize the fine differences between English phonemes, was used as a model for the construction of the auditory discrimination test. The test which was prepared for this study contained a total of 40 one-syllable word pairs. The first three were practice items which were not included in the measurement. Of the remaining 40 word pairs, 30 pairs differed in a single phoneme, but ten pairs did not differ; comparisons were made between thirteen initial consonants (such as ten and den), four medial vowels (such as hot and hut), thirteen final consonants (such as cash and catch), and ten false choices (such as house and house) (Table 2).

TABLE 2

TEST OF AUDITORY DISCRIMINATION

\begin{tabular}{|l|c|l|l|l|l|}
\hline Item & S & D & Item & S & D \\
\hline 1. jam-jam & $\sqrt{ }$ & & 23. sheet - cheat & & $\sqrt{ }$ \\
\hline 2. lake - sake & & $\sqrt{ }$ & 24. sink - zinc & & $\sqrt{ }$ \\
\hline 3. house - house & $\sqrt{ }$ & & 25. big - big & $\sqrt{ }$ & \\
\hline 4. home - dome & & $\sqrt{ }$ & 26. fool - full & & $\sqrt{ }$ \\
\hline 5. ten - den & & $\sqrt{ }$ & 27. safe - save & & $\sqrt{ }$ \\
\hline 6. coat - code & & $\sqrt{ }$ & 28. rouge - rule & & $\sqrt{ }$ \\
\hline 7. back - bag & & $\sqrt{ }$ & 29. live - live & $\sqrt{ }$ & \\
\hline 8. sheep - ship & & $\sqrt{ }$ & 30. choke - joke & & $\sqrt{ }$ \\
\hline 9. bit - bit & $\sqrt{ }$ & & 31. class - glass & & $\sqrt{ }$ \\
\hline 10. tin - thin & & $\sqrt{ }$ & 32. sleep - sleep & $\sqrt{ }$ & \\
\hline 11. west - vest & & $\sqrt{ }$ & 33. cot - caught & & $\sqrt{ }$ \\
\hline 12. ring - ring & $\sqrt{ }$ & & 34. place - plays & & $\sqrt{ }$ \\
\hline 13. thing- think & & $\sqrt{ }$ & 35. close - clothe & & $\sqrt{ }$ \\
\hline 14. rope - robe & & $\sqrt{ }$ & 36. cup - cup & $\sqrt{ }$ & \\
\hline 15. cheep - cheep & $\sqrt{ }$ & & 37. pin - bin & & $\sqrt{ }$ \\
\hline 16. hot - hut & & $\sqrt{ }$ & 38. red - led & & $\sqrt{ }$ \\
\hline 17. day - they & & $\sqrt{ }$ & 39. seem - seem & $\sqrt{ }$ & \\
\hline 18. fine - vine & & $\sqrt{ }$ & 40. sin - sing & & $\sqrt{ }$ \\
\hline 19. food - food & $\sqrt{ }$ & & 41. sum - sun & & $\sqrt{ }$ \\
\hline 20. cash - catch & & $\sqrt{ }$ & 42. lease - leash & & $\sqrt{ }$ \\
\hline 21. perch - purge & & $\sqrt{ }$ & 43. young - tongue & & $\sqrt{ }$ \\
\hline 22. care-care & $\sqrt{ }$ & & & & \\
\hline
\end{tabular}

Although the effect of L1 on L2 perception and production of speech sounds was not intended to be measured in this 
study, some English sounds which are non-existent in Persian were placed in contrast to English sounds existing in Persian, such as tin-thin for consonants and sheep-ship for vowels, in order to sharpen the discriminative power of the test. The test was recorded by the same female native American who recorded the test of oral production. Each pair was followed by a pause. During the pause the subject was to respond "same" or "different", which was recorded on tape. The examiner checked the accuracy of the responses when the testing procedure was finished.

\section{Procedure, Data Collection, and Data Analysis}

A soundproof language lab was used for data collection so that no extraneous noise could interfere. Subjects took part in the test of oral production individually followed by the test of auditory discrimination. The whole procedure took 20 minutes. Instructions were given in native tongue, first for the test of oral production followed by some practice both in Persian and English. When the examiner was certain that the subjects were quite familiar with the procedure, she started the actual test. The subjects listened to each word and then pronounced the word which was then recorded on the student tape. Following this, the test of auditory discrimination started immediately. The same procedure of explanation, practice, and recording was used for this test. The judges who had shown to agree on $91 \%$ of their decisions in a pilot test conducted before grading the actual test were trained to respond to the sounds which were singled out in the script of the recorded words (Table 1). Two ANOVAs were administered to find the relationship between age, gender, and language learning. The first one compared two groups of children and adults. The dependent variables were phonetic discrimination and oral production of English sounds. The two groups compared in the second ANOVA were males versus females and the dependent variables were discrimination and production of English sounds.

\section{RESULTS AND DISCUSSION}

This study planned to answer some questions regarding the effect of age and gender on perception and production of English speech sounds. The descriptive statistics for two tests of auditory discrimination and oral reproduction of sounds for groups of children, adults, males and females are illustrated in Table 3.

TABLE 3

DESCRIPTIVE STATISTICS

\begin{tabular}{|l|l|l|l|}
\hline Group & $\mathrm{N}$ & Mean & SD \\
\hline Adults P & 30 & 29.6333 & 4.1728 \\
\hline Adults D & 30 & 26.0889 & 5.7502 \\
\hline Children P & 30 & 29.6333 & 5.1427 \\
\hline Children D & 30 & 27.1043 & 2.6040 \\
\hline Male P & 30 & 29.7333 & 5.0030 \\
\hline Male D & 30 & 26.3934 & 4.5427 \\
\hline Female P & 30 & 29.5333 & 4.3370 \\
\hline Female D & 30 & 26.7933 & 4.4328 \\
\hline
\end{tabular}

The first hypothesis in this study stated that there is no difference between children and adults regarding perception and production of speech sounds. Two ANOVAs were performed. The first univariate analysis of variance indicated that neither group performed better than the other one; therefore, the first null hypothesis was accepted. Using an alpha level of .01, we can determine that the difference between performances of children and adults was not significant $(\mathrm{p}=.544$, $\mathrm{F}=.370)$ (Table 4).

TABLE 4

RESULTS OF THE ANOVA BETWEEN ADULTS AND CHILDREN

\begin{tabular}{|l|l|l|l|l|l|}
\hline Source & Sum of Squares & df & Mean Square & F & Sig. \\
\hline Group & 7.734 & 1 & 7.734 & .370 & .544 \\
\hline Variable & 276.651 & 1 & 276.651 & 13.220 & .000 \\
\hline Error & 2427.452 & 116 & 20.926 & & \\
\hline Total & 97573.755 & 120 & & & \\
\hline
\end{tabular}

This means that children and adults have equal chances for success in production and perception of sounds when just exposed to the English language. The results rejected studies such as those discussed in Guasti (2002), Oyama (1976), Cochrane and Sachs (1979), which indicate that children had an advantage over adults in learning second language sounds because of biological characteristics.

The results did neither confirm the studies such as those of Stern (1976), Asher and Price (1967), Snow and Hoefnagel-Hoble (1978), and Rosenman (1987), who supported the idea that adults, because of their cognitive advantage, are more successful than children. The findings, however, support Stolten and Engstrand (2002) who observed no significant age-related differences in their study.

The second hypothesis was that either males or females would perform better in the assigned tasks. Using an alpha level of .01, we can determine that the difference between performances of males and females was not significant $(\mathrm{p}=.905, \mathrm{~F}=.014)($ Table 5). 
TABLE 5

RESULTS OF THE ANOVA BETWEEN MALES AND FEMALES

\begin{tabular}{|l|l|l|l|l|l|}
\hline Source & Sum of Squares & df & Mean Square & F & Sig. \\
\hline Group & 300 & 1 & .300 & .014 & .905 \\
\hline Variable & 277.245 & 1 & 277.245 & 13.182 & .000 \\
\hline Error & 2439.638 & 116 & 21.031 & & \\
\hline Total & 97563.079 & 120 & & & \\
\hline
\end{tabular}

This shows that gender is not a significant factor regarding perception and production of English sounds and therefore, the second null hypothesis which states that there is no difference between children and adults regarding perception and production of speech sounds is also accepted. This outcome contradicts that of Stolten and Engstrand (2002) who judged younger women as less dialectal than men of the same generation. Within group individual differences can nevertheless, be depicted.

A comparison made between tests of auditory discrimination and oral reproduction revealed that the difference between the two tests was significant. Comparison of the means (Table 3) revealed that children, adults, males, and females all performed significantly better in the production test when compared to the discrimination test in both child/adult and male/female comparisons. Therefore, the third hypothesis stating that there is no difference between auditory discrimination and oral production of sounds as two aspects of foreign language skills was rejected. Levels of significance were $\mathrm{p}=000, \mathrm{~F}=13.220$ for the age-related comparison (Table 4) and $\mathrm{p}=000, \mathrm{~F}=13.182$ (Table 5) for the gender-related one. The superior level of production over discrimination is illustrated in Figure 1.

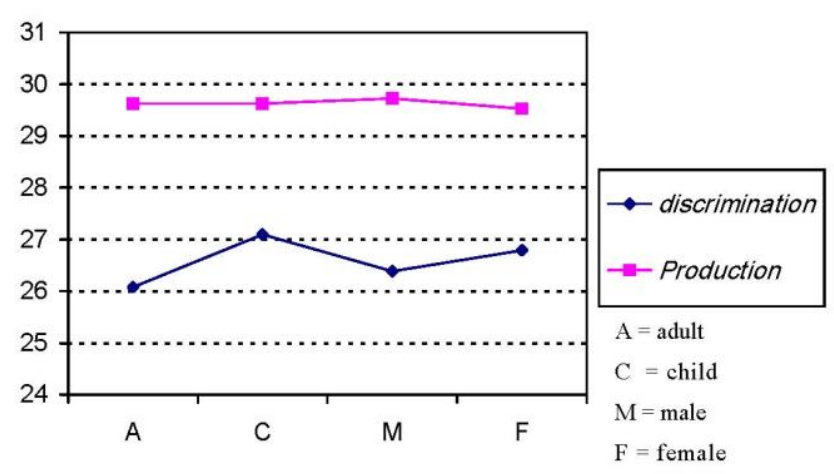

Figure 1. The Comparison between Tests of Production and Discrimination

The superiority of the production test could answer the question regarding the ability of learners to adequately pronounce sounds which are not well perceived. It supports the idea that a good perception is not necessarily a prerequisite to accurate pronunciations. The researcher agrees with Mack (1989) and Sheldon (1985) who believe that the social consequences of non-native production are more important than those of non-native perception and, therefore, accurate productions are found where perception can be different from monolinguals. This finding also supports Llisterri (1995) who concludes that, in certain cases, the production of L2 sounds might precede their perception, Caramazza et al. (1973) who found that bilingual speakers can better adapt their production than their perception in their non-dominant language, and Mack (1989) who found evidence that bilingual production can be more accurate than perception. The superiority of production test, however, contradicts that of Flege (1991) who believes perception of a new phonetic contrast must necessarily precede its production and Polivanov (1931, cited in Llisterri, 1995) who accounts for the L1 effect on SL pronunciation. Works discussing the effects of training based on production vs. training based on perceptual strategies (Catford \& Pisoni, 1970; Weiss, 1992) which imply that good production abilities may contribute to a better discrimination of L2 sounds are worth noticing as they may be relevant to the practical implications of the present research.

\section{CONCLUSION}

The findings of this study reveal that age is not a significant factor in learning the English language sounds. Persian children and adults showed to have similar chances for success in learning English sounds as they performed equally well in discrimination and production of these sounds. Moreover, no superiority was found regarding the gender factor. Both males and females discriminated and produced English sounds equally well.

One noticeable result was the superiority of production of sounds over their discrimination. All groups of adults, children, males, and females performed better in tests of production of sounds than discrimination (Table $3 \&$ figure 1 ). This implies that perception of a phonetic contrast does not necessarily precede its production. In other words, different factors including social consequences (Mack, 1989; Sheldon, 1985) may bring about better production of sounds which may not have been well perceived. This is a hypothesis which could be tested in future studies. 


\section{THEORETICAL AND PEDAGOGICAL IMPLICATIONS}

The results of this research have both theoretical and practical implications. Theoretically, the results can expand the scope of the 'age issue' implying that there is no difference between how children and adults learn an SL; more specifically the way they perceive and produce sounds when they are exposed to them. It can, therefore, be stated that there is still room for an innate faculty to continue its work in adulthood.

The practical issue concerns the appropriate time to begin instruction in a second/foreign language environment. The outcomes of this research put no limits on the age of instruction. Foreign language instruction can be introduced at primary school, secondary school, or higher levels assuring success at all ages. Possible unsuccessful cases can be attributed to the learner's individual characteristics. While certain children can perform better than certain adults, the opposite case is quite as probable. Regarding the gender issue, there is no difference between males and females with respect to production and perception of English sounds. However, the training based on production seems to be more fruitful than the one on perception. Finally, it can be stated that teachers may instruct English sounds regardless of age and gender differences. However, individual differences are to be considered. The researcher hopes that this study will be of use to both language planners and instructors.

\section{LIMITATIONS AND SUGGESTIONS FOR FURTHER STUDY}

This study was limited in the number of subjects; further studies may include larger samples. This study tested only English language as its target; studies including other languages can confirm or reject the findings of this research. This research had only Persian speakers as subjects and did not intend to measure the effect of L1 on L2 perception and production of speech sounds; other researchers may include native speakers of other languages and also consider the effect of L1 on L2 in order to reach at a more conclusive theoretical background. Cross-sectional studies, can be affected by cohort effects, meaning that differences between age groups (cohorts) may result from environmental events (Ateah et. al. 2009); conducting similar studies with different age groups and environmental events may moderate the cohort effects.

\section{REFERENCES}

[1] Ateah, C.A., Kail, R.V., Cavanaugh, J.C. (2009). Human Development A Life-Span View, Nelson Education Ltd.

[2] Asher, J., \& Price, B. (1967).The learning strategy of total physical response: some age differences. Child Development, 38, 1219-1227.

[3] Bickerton, D. (1981). Roots of Language. Ann Arbor, MI: Karoma Publishers.

[4] Birdsong, D. (1999). Introduction: Whys and why nots of the Critical Period Hypothesis. In D. Birdsong (Ed.), Second language acquisition and the Critical Period Hypothesis (pp. 1-22) Mahwah, NJ: Elbaum.

[5] Bongaerts, T. (1999)..Ultimate attainment in foreign language pronunciation: The case of very advanced late foreign language learners. In D. Birdsong (Ed.), Second Language Acquisition and the Critical Period Hypothesis. (pp.133-1590.) Mahwag. Nj: Elbaum.

[6] Briére, E. (1966). An Investigation of Phonological Interference. Language 42, 4: 769-796.

[7] Byrd, D. (1994). Relation of sex and dialect to reduction. Speech Communication, 15, 39-54.

[8] Caramazza, A., Yeni-Komshin, G., Zuriff, E., \& Carbone, E. (1973). The Acquisition of a New Phonological Contrast: The Case of Stop Consonants in French-English Bilinguals. Journal of the Acoustical Society of America, 54, 2: 421-428.

[9] Catford, J.C., \& Pisoni, D. (1970). Auditory vs. Articulatory Training in Exotic Sounds. Modern Language Journal, 54, 477-481.

[10] Cochrane, R., \& Sachs, J. (1979).Phonological learning by children and adults in a laboratory setting. Language and Speech, 22(2), 145-149.

[11] Flege, J. E. (1987).A critical period for learning to pronounce foreign languages? Applied Linguistics, 8(2), 162-77.

[12] Flege, J. E. (1991).Perception and Production: The Relevance of Phonetic Input to L2 Phonological Learning. In Hueber, T., \& Ferguson, C. (Eds.), Crosscurrents in Second Language Acquisition and Linguistic Theories (pp. 249-289). Amsterdam: John Benjamins.

[13] Flege, J. E., Yeni-Komshian, G. H., and Liu, S. (1999). Age Constraints on second-language acquisition. Journal of Memory and Language, 41, 78-104.

[14] Guasti, M.T. (2002). Language Acquisition. Massachusetts Institute of Technology. Library of Congress Cataloging-in-Publication Data.

[15] Guiora, A. Z., Brannon., R. C., \& Dull., C. Y. (1972).Empathy and second language learning. Language Learning, 22, 111-130.

[16] Hareley, B. (1986). Age and second Language Acquisition. Clevedon: Multilingual Matters.

[17] Hudson, G. (2000). Essential Introductory Linguistics. Blackwell Publishers Inc.

[18] Johnson, J. S. (1992). Critical period effects in second language acquisition: The effect of written versus auditory materials on the assessment of grammatical competence. Language Learning, 42, 217-248.

[19] Kramer, C. (1978). Perceptions of female and male speech. Language and Speech, 20, 151-161.

[20] Lenneberg, F. H. (1967). Biological foundations of language. New York: Wiley.

[21] Llisterri, J. (1995). Relationships between Speech Production and Speech Perception in a Second Language. In Elenius, K., \& Branderud, P. (Eds.), Proceedings of the XIIIth International Congress of Phonetic Sciences (pp. 92-99). Stockholm, Sweden, 13-19 August 1995. Stockholm: KTH/ Stockholm University.

[22] Long, M. H. (1990b).Maturational constraints on language development. Studies in Second Language Acquisition, 12, $251-285$. 
[23] Mack, M. (1989).Consonant and vowel perception and production: Early English- French bilinguals and English monolinguals. Perception \& Psychophysics, 46(2), 187-200.

[24] Marinova-Todd, S. H., Marshall, D. B., \& Snow, C. E. (2000).Three misconceptions about age and L2 learning. TESOL Quarterly, 34, 9-34.

[25] Morris, B. S. K., \& Gerstman, L. J. (1986). Age Contrasts in the learning of language-relevant materials: Some challenges to critical period hypotheses. Language Learning, 36, 311-352.

[26] Neufeld, G. (1979).Toward a theory of language learning ability. Language Learning, 29, 227-241.

[27] Neufeld, G. (1988). Phonological asymmetry in second language learning and performance. Language Learning, 38(4), 531-559.

[28] Oyama, W. (1976). A sensitive period for the acquisition of a non-native phonological system. Journal of Psycholinguistics Research, 5, 261- 283.

[29] Patkowski, M. S. (1990). Age and accent in a second language: A reply to James Emil Flege. Applied Linguistics, 11, 73-89.

[30] Rosenman, A. A. (1987). The Relationship between Auditory Discrimination and Oral Production of Spanish Sounds in Children and Adults. Journal of Psycholinguistic Research. Vol. 16, No. 6.

[31] Scovel, T. (1988). A Time to Speak: A psycholinguistic Inquiry into the Critical Period for Human Speech. New York: Newbury House Publishers.

[32] Sheldon, A. (1985).The relationship between production and perception of the /r/-/l/ contrast in Korean Adults learning English. A reply to Borden, Gerber and Milsark. Language Learning, 35(1), 107-113.

[33] Singleton, D., \& Lengyel, Z. (1995). (Eds.). The Age Factor in Second Language Acquisition: A Critical Look at the Critical Period Hypothesis. Clevedon: Multilingual Matters.

[34] Snow, C., \& Hoefnages-Hohle, M. (1978).The critical period for language acquisition Evidence from second language learning. Child Development, 49, 1114-1128.

[35] Stern, H. (1976).Optimal age: Myth or reality? Canadian Modern Language Review, 32, 283-294.

[36] StÖlten, K., \& Extrand, O. (2002). Effects of Sex and age in the Arjeplogdialedt: a listening test and measurements of preaspiration and VOT. Speech, Music and Hearing. TMH-QPSR Vol. 44- Fonetik 2002.

[37] Trudgill, P. (1972). Sex covert prestige, and linguistic Change in the Urban British English of Norwich. Language in Society, 1, 179-195.

[38] Weiss, W. (1992). Perception and Production in Accent Training. Revue de Phonétique Appliquée, 102, 69-81.

[39] Wepman Auditory Discrimination Test. Western Psychological Services, 12031 Wilshire Boulevard, Los Angeles, CA 90025. (1958, 1973).

Zohreh Kassaian was born in Isfahan Iran. She received her BA degree in English Language and Literature from The University of Isfahan, Isfahan, Iran in 1973 (as a top student); her MA in Teaching English as a Second Language from the University of Shiraz, Shiraz, Iran in 1987; and her PhD in Teaching English as a Second Language from Islamic Azad University, Tehran, Iran in1996.

She is an assistant professor in the English Department of the Faculty of Foreign languages at the University of Isfahan. She is a permanent academic member and has held this position since 1978. She has participated in more than 20 national and international conferences and has more than 20 articles and several books published. Her subjects of interest are Psycholinguistics, Neurolinguistics, Applied Linguistics, Phonetics, and Translation.

Dr. Kassaian has been a member of several professional societies including International Systemic Functional Linguistics, Iran Society of Teaching English Language and Literature, and The International Society of Scientific Collaboration for Iran Recognition. 